\title{
Toward Sustainable Development: Implications for Population Aging and the Wellbeing of Elderly Women in Developing Countries
}

\author{
Jennifer C. Cornman \\ University of Michigan
}

\begin{abstract}
Attaining sustainable development has significant implications for population age structure, family structure and the wellbeing of elderly women. If one of the primary goals of sustainable development is reducing fertility to attain a population growth rate which can be supported by the Earth's resources, then working toward sustainable development will lead to an aging population. This demographic change coupled with other impacts of working toward sustainable development could significantly affect the status and wellbeing of elderly women. Drawing on examples primarily from the Asian setting, this paper will examine population aging and what this demographic change may mean for elderly women in developing areas.
\end{abstract}

\section{INTRODUCTION}

Proponents of sustainable development assert that human population growth and resource consumption are reaching unsustainable levels (Kitatani, 1990; Ness, forthcoming). In 1990 the world's population reached 5.2 billion and is projected to reach 8.5 billion by 2025 with 93 of 100 births occurring in developing countries (ESCAP, 1989). The leaders in many developing countries realize that, in order to relieve the pressure on

Please address correspondence to Jennifer C. Cornman, M.A., Population Studies Center, 1225 S. University, University of Michigan, Ann Arbor, MI 48104-2590.

Population and Environment: A Journal of Interdisciplinary Studies

Volume 18, Number 2, November 1996

(C) 1996 Human Sciences Press, Inc. 
agricultural lands, energy sources, watersheds and forests, population growth must be slowed. Also, in countries which have large populations, improvements in per capital income and the reduction of poverty may not be possible without slowing population growth (Kitatani, 1990; ESCAP, 1989). Therefore, to attain sustainable development, fertility levels must decline.

In formulating and implementing policies to reach sustainable development, countries should also keep in mind the outcomes of these policies. If sustainable development entails reducing fertility, then attaining sustainable development will lead to an aging population. Population aging is primarily a result of fertility and mortality declines, both goals of sustainable development. Many countries in the developing world have already begun to show signs of aging populations. Most countries in SouthEast Asia, for example, have completed their fertility transition and are now experiencing increasing numbers and proportions of people aged 65 and over. Several countries in South Asia are also experiencing fertility declines as well as increasing proportions of elderly. Drawing on examples primarily from the Asian setting, this paper will examine the impacts of sustainable development on population aging and what this demographic change may mean for elderly women in developing areas.

\section{POPULATION AGING AND AGE STRUCTURE}

Population aging is the process of changes in the age structure where proportions of people in older age groups (generally $65+$ ) increase and the proportions of people in younger age groups decrease (Nair, 1987; United Nations Sectretariat, 1994). Fertility and mortality are the primary demographic factors which affect the age structure of a population.' Both the number of persons ever born under particular fertility conditions as well as the number and proportion who survive at any age under different mortality regimes (Coldman, 1986) affect a population's age structure.

When fertility and mortality rates are high, a population's age structure is young. With high rates of fertility, there is a large base of people in the younger age groups and, with high mortality, relatively fewer people survive to older ages. The proportion of the population in older age groups, therefore, is small.

With declining mortality and high fertility, the age structure of the population becomes younger. Mortality first begins to decline as infectious and parasitic diseases are brought under control, ${ }^{2}$ primarily improving mortality at the youngest ages (Preston, 1980; Stolnitz, 1982). More children, there- 
JENNIFER C. CORNMAN

fore, survive through childhood, significantly increasing the proportion of young people in the population. In addition, more female children live to child-bearing age, increasing the numbers of women having children, further reducing the age of the population.

When mortality is low or declining and fertility starts to decline, a population begins to get older. The level of fertility is the most significant factor affecting the numbers being born into a population. ${ }^{3}$ Both the level of age-specific fertility and the numbers of women in their child-bearing years affect the numbers of infants being born. When fertility levels decline, there is a proportional decline in the number of births entering the bottom of the age pyramid. Then, when this smaller cohort of births reaches the reproductive age groups, there are fewer women alive to have children. This, coupled with lower age-specific fertility rates, leads to even smaller birth cohorts entering the population, which, in turn, means that the older age groups will constitute a larger proportion of the population. Mortality, although having a smaller effect, also ages the population through increased survivorship.

In general, when replacement or below replacement fertility levels ${ }^{4}$ are reached and mortality remains low or continues to decline, mortality is the primary factor affecting age structure. Greater survival to older ages combined with low levels of fertility result in an increase in the proportions of people in the older age groups. In this case, a population is said to be aging from the top of the age structure.

\section{ILLUSTRATION OF THE IMPACT OF FERTILITY AND MORTALITY DECLINES}

To illustrate the impacts of fertility and mortality on population age structure, two simulations are examined. In the first simulation mortality is held constant and fertility declines. The second simulation holds fertility constant and mortality declines. Figure 1 shows the effects of holding mortality constant and decreasing fertility. The first pyramid has an age-sex distribution common in many less developed countries which have already experienced some declines in fertility. The assumed constant life expectancy at birth is about 57 for both sexes combined and the Total Fertility Rate (TFR) declines from 4.2 in Pyramid 1 to 2.1 in Pyramid 3. The projection covers a total of 40 years. ${ }^{5}$

It is clear from this picture that fertility has a significant impact on population aging. The proportion of the population age 0-14 decreases from $36.0 \%$ in the first pyramid to $33.3 \%$ in the second pyramid, to 23.3 in 


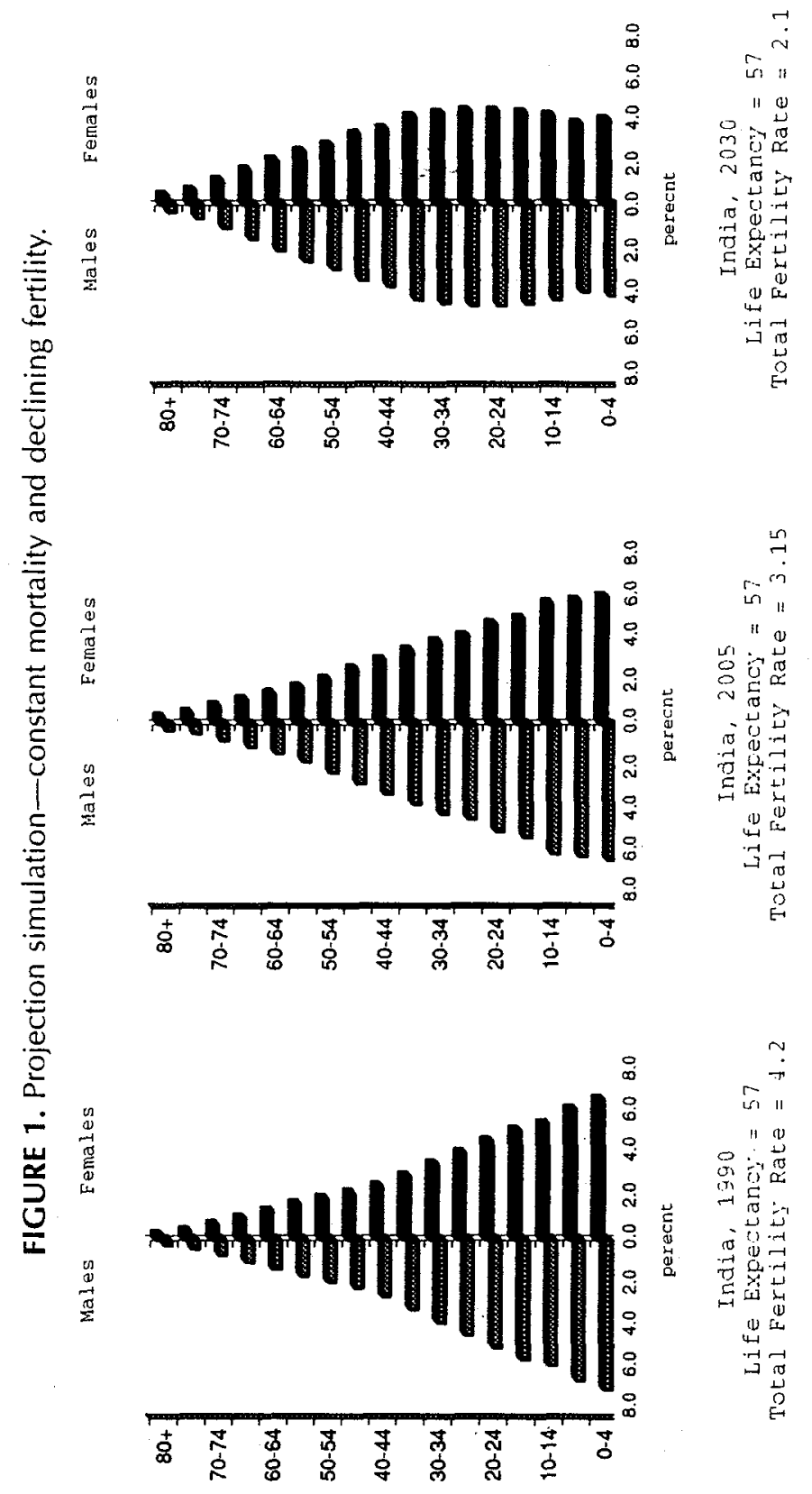




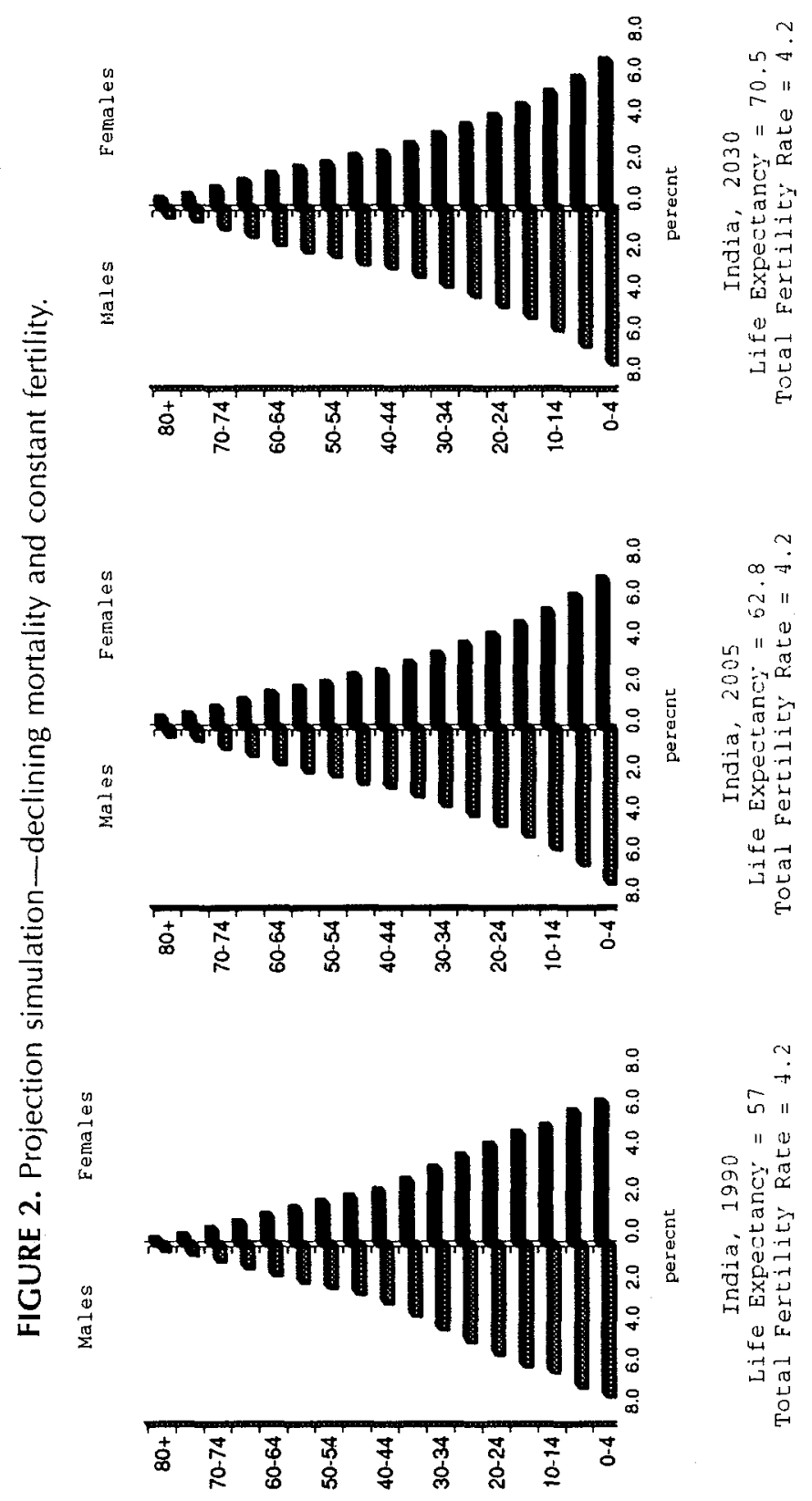


the final pyramid. The proportion of the population ages 65 and over increases from $4.5 \%$ in the first pyramid to $5.0 \%$ in the second, to $8.6 \%$ in the last, almost doubling the proportion of the population in this age group. Although this simulation simplifies some of the subtleties of population aging, it clearly shows that reducing fertility, one factor involved in working toward sustainable development, will lead to an aging population.

Figure 2 shows a similar simulation holding fertility constant and allowing for mortality to improve. The base population is the same as in Figure 1. It has a TFR of 4.2 and a life expectancy at birth of 57 years. Over a 40 year simulation period, the life expectancy at birth increases from 57 years to 71 years for both sexes combined.

Figure 2 shows that, compared to the effects of fertility decline on a base population, mortality has relatively little effect on the aging of a population when fertility is held constant at a moderately high level. The proportion of the population age $0-14$ remains constant at about $36 \%$ and the proportion of elderly only increases by 2 percentage points. It is important to note, however, that if fertility were held constant at a lower level, mortality would have more of an effect on the age structure. In another simulation (not shown here) where fertility is held constant at 2.8 , the proportion of the population aged 65 and over increases from $4.5 \%$ to $10.3 \%$ over the 40 year simulation period. This illustrates that as fertility approaches replacement levels the impact of improved mortality on population aging increases.

\section{POPULATION AGING IN ASIA}

As noted above, population aging is primarily indicated by decreasing proportions of people in younger age groups and increasing proportions in older age groups. Yet, in many developing countries, the shifts in the dependency ratios ${ }^{6}$ and the proportions of a population who are elderly may not occur for quite some time after the initial declines in fertility. This is due to cohort succession. It takes time for large birth cohorts to work their way through the age structure. It is not only important for these large cohorts to age their way out of the $0-15$ age group, but they also must age their way out of the child-bearing age groups. Large cohorts in the childbearing years will continue to produce large birth cohorts, even if fertility is low. Yet, when these large cohorts in the child-bearing years get older, they significantly increase the numbers of older people in the population and can do so without significantly increasing their proportion of the total. For 
JENNIFER C. CORNMAN

example, in India in 1990 there were 38.4 million people age 65 and over and in 2020 it is projected that there will be 71.7 million people 65 and over, an increase of 33.3 million (United Nations, 1993). While this is a large increase in absolute numbers, the percent of the population who are elderly only increases from 4.5 to 7.4 (United Nations, 1993). So, when considering population aging, it is important to consider not only the proportions of elderly, but also the increase in absolute numbers (Nair, 1987; Chanana \& Talwar, 1986).

Table 1 shows various indicators of population aging in selected countries in East, Southeast, and South Asia, demonstrating that population aging varies across these areas. The most significant population aging in these three regions can be seen in Japan where the life expectancy at birth (for men and women combined) in 1990 is 78.7 and where approximately $17 \%$ of the population is over age 60 . Life expectancy is projected to increase to 81.3 in 2020 when nearly $30 \%$ of Japan's population will be age 60 and over. In general, of the three Asian regions in Table 1, East Asia has the highest life expectancies and the largest proportions of their populations who are elderly. South Asia tends to have the lowest life expectancies at birth of the three regions and the lowest percent of elderly in their population. The life expectancy in Bangladesh, for instance, was only 52.8 in 1990 and only $4.9 \%$ of the population was age 65 and over. Sri Lanka is an exception to this region. In 1990 Sri Lanka's total fertility rate was already at 2.48 and life expectancy was 71.6, figures which are closer to those of China and Korea in East Asia than to those of India and Bangladesh. It is worthy to note, however, that by 2020 , the elderly will comprise greater than $10 \%$ of the population in 8 out of the 9 Asian countries listed in Table 1. (Bangladesh is the exception in this Table.) It is clear from these figures that many Asian populations are aging or beginning to age.

\section{WOMEN AND POPULATION AGING}

Fertility and mortality declines, together with economic and social development, raise important issues for the care and social and economic wellbeing of older people in developing countries, particularly for women. Exactly how these demographic changes will affect elderly women greatly depends on the culture and rates of development within each country. The following issues, however, indicate the potential impacts of demographic change and development on women's lives.

First, the numbers of elderly women and the proportion of elderly who are women are significantly increasing. This is occurring, in part, because 


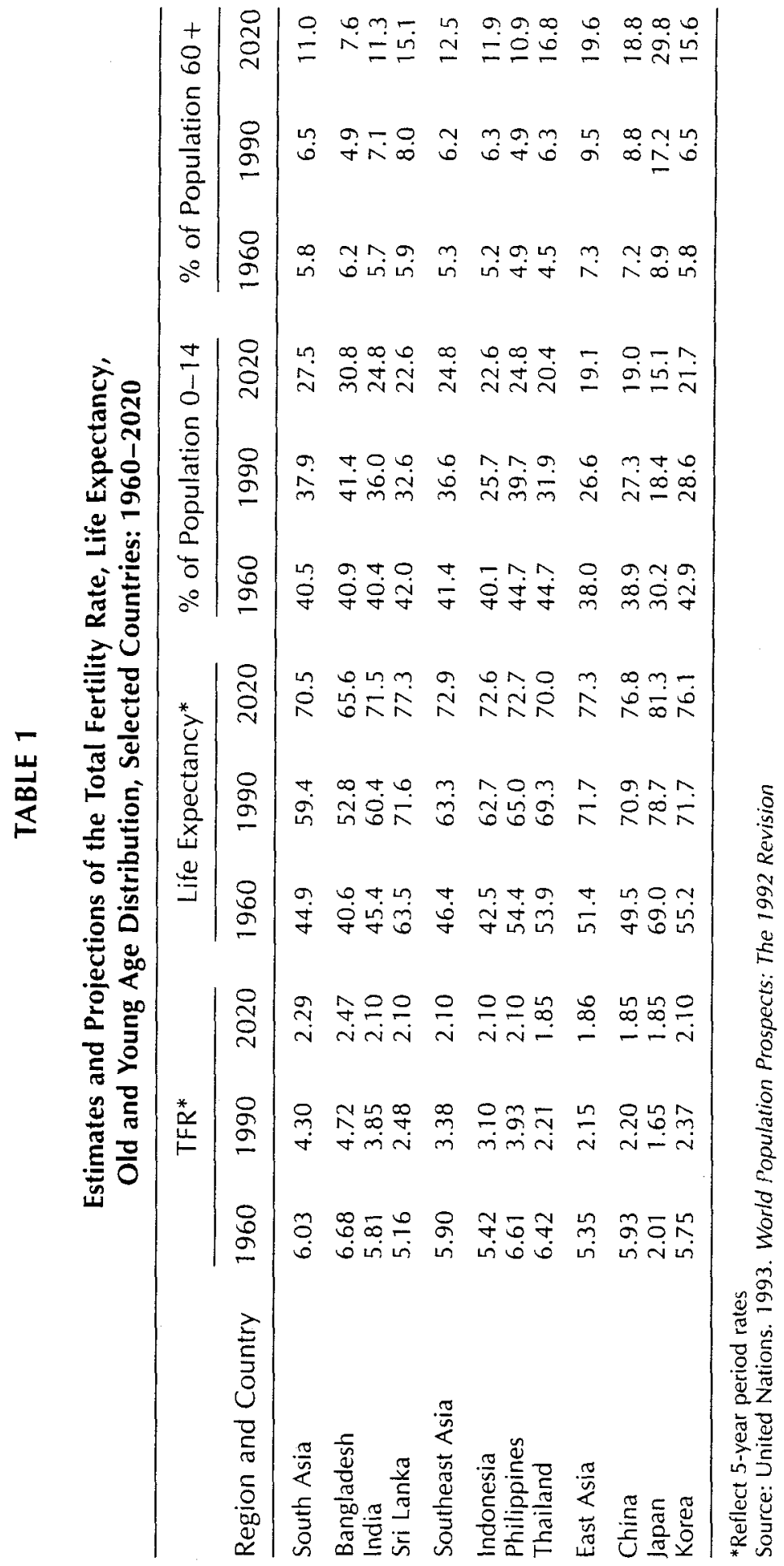


JENNIFER C. CORNMAN

as fertility declines, maternal and infant mortality tends to decline, increasing the number of women who survive to older ages. Also, female life expectancies at almost every age are increasing. Finally, women have higher life expectancies than men and, in general, have lower age-specific mortality rates at almost every age. Women, therefore, will comprise a larger proportion of elderly populations.

A second important consideration is the rate of widowhood in developing countries. Not only are significant proportions of women aged 60 and over widowed, but women are also more likely than men to be widowed at older ages and to live longer portions of their lives in dependent states (ESCAP, 1987). Martin (1990), for example, notes that despite the fact that South Asian Countries have relatively high sex ratios among the elderly (96 in Nepal and 123 in Bangladesh compared to 60 in China), at least half of the women are widowed while three-quarters of the males are still married. Using data from the 1989 Taiwan Survey of Health and Living Status of the Elderly, Hermalin, Ofstedal, and Chi (1992) report that while $85 \%$ of males age $60-69$ are currently married, only $63 \%$ of females have living spouses. This gap widens for ages 70 and over with $68 \%$ of males having a living spouse compared to only $34 \%$ of females. These trends occur because of the greater longevity of women; because women marry men who are older; and/or because women have lower rates of remarriage than men (ESCAP, 1987; Martin, 1990; Hermalin, Ofstedal, \& Chi, 1992).

$A$ third issue is the fact that elderly women traditionally do not have histories of longterm formal labor force participation, nor have they obtained high levels of education. As a result they are particularly vulnerable and dependent on other family members (ESCAP, 1987; Domingo, 1994). Even when women do work, they are often not covered by pensions because they primarily work in the lowest ranks of the employment structure or in the informal sector (Domingo, 1992; Watana, 1994; Chang, 1994). This often means that women are completely reliant on their husbands or male kin for support in old age, especially widows whose financial status usually declines after her husband's death.

Finally, declines in fertility and mortality not only change the structure of the population but also alter the structure of families and the traditional dynamics of caring for elderly relatives. These four factors, combined with the effects of economic development, significantly impact the ability of the family, the traditional and primary caregiving institution for the elderly, to care for aging relatives. This is particularly important for women because they almost entirely depend on family support in old age. 
POPULATION AND ENVIRONMENT

\section{FAMILY, ECONOMIC CHANGE AND SUPPORT FOR THE ELDERLY}

Because fertility and mortality also affect the structure of families, it is necessary that the structure of the family changes as the age structure of a population changes. As a population experiences the transition from high mortality-high fertility regimes to low mortality-low fertility regimes, the family structure "verticalizes." There is a decline in the proportions of kin in each generation of a family and an increase in the proportions of families consisting of parents, grandparents and great grandparents (Goldman, 1986). This "verticalization" of age and family structures will have significant effects on kin availability throughout the life course of an individual as well as on the size and composition of an individual's household (Young, 1986).

These changes in the family structure have important implications for the caregiving of elderly women. First, reducing family size reduces the number of people who can share in the economic and emotional burden of caring for an aging parent. While an adult child may want to continue to care for an aging parent, the burden may be too great for one person to handle. Lee and Palloni (1992) note that while family status will not greatly deteriorate for elderly women in Korea over the next few decades, shortages of support could occur because there are fewer children available. In Taiwan, where support for the elderly is generally shared between an elderly parent's adult children, it may be expected that family coverage of the elderly's needs will decline given the competing demands faced by smaller cohorts of educated and occupationally mobile children (Hermalin, Ofstedal \& Chang, 1992).

Coresidence of aging parents and their adult children is also affected by changes in family structure. Although several studies on Asian elderly (Martin, 1990; Hashimoto, 1991; Domingo, 1994; Chayovan, 1994) have shown that recent declines in family size have not yet lead to lower probabilities of elderly coresiding with adult children, there is no indication of how long this tradition will necessarily be maintained under future economic and demographic conditions. For example, when mortality levels are high, an adult child may not coreside with an older mother for a significant amount of time. An adult child's parent may not live to a very old age, so the possible period of coresidence may be short. When mortality declines, however, coresidence with an older parent could last for a much longer period of time because the period of joint survival of adult children and their older parent increases. This increase could place a larger burden on families, especially small families. ${ }^{8}$ 
Changing demographic conditions will affect the amount of time spent in various family statuses. One effect of lower fertility levels is the concentration of the number of years and proportion of life a woman spends as a mother of dependent children (Watkins, 1987). Women, therefore, may spend less time in a role that once primarily defined their lives. This can have both positive and negative effects depending on the cultural setting. For women who are allowed to work outside the family, lower fertility gives women more time for non-domestic activities. On the other hand, for women who are more secluded it could mean that more time will be spent in a position with less importance and respect.

Economic development, on its own and with its interactions with family life, also impact family caregiving. One outcome of industrialization and urbanization is increasing levels of education. More schooling increases the amount of time children spend and the amount of socialization occurring outside the family (Mason, 1991; Fricke et al., 1994). Increasing education can serve to undermine the control parents have over their children and reduce feelings of filial piety, weakening the responsibility children may feel for taking care of aging parents. Chayovan (1994) notes that in Thailand the normative obligations of family support for elderly parents may be weakening.

Changes in the mode of production caused by increasing industrialization can have similar effects. As children become more economically independent by working outside the family, parental control over their children's lives may be reduced. In addition, as the mode of production is shifted away from the family, children may be more mobile than in the past. These possible changes combined with lower fertility could reduce the family care available for the aged.

The shift in the mode of production may also lead to higher rates of labor force participation of middle aged wives, the traditional caregivers of aging parents. This trend would place additional burdens on the family care system. Increasing labor force participation of women in reproductive ages implies that it may be more difficult for women to effectively assume the multiple roles of mother, employee and elderly caregiver. Even in cases where sons provide some assistance, it is often women who provide assistance with the more time consuming tasks.

In Singapore, for instance, sons gave financial assistance and emergency help while daughters provided more emotional and instrumental help (Mehta, 1994). Research on Taiwanese elderly also show gender differences in the types of support provided (Hermalin, Ofstedal, \& Chang, 1992; Hermalin, Ofstedal, \& Lee, 1992). These studies found that daughters-in-law (and spouses) are the most important providers of assistance 
POPULATION AND ENVIRONMENT

with daily activities while it was most common for sons to give financial support. As mentioned previously, declines in fertility reduce the time women spend as mothers of dependent children. Improving life expectancies of parents and other relatives, however, will require more time and effort for family care by women, especially when there are not social services available to assist with the care.

\section{POLICY IMPLICATIONS}

In the past population aging has not been considered in population policy. This was primarily due to the fact that population aging is generally measured by increasing proportions of people over age 60 or 65 . In many Asian countries the proportions of elderly have not necessarily been increasing at significant rates. Issues of aging, therefore, were not considered important. In addition, when resources are scarce, population aging is a low priority, especially when it is assumed that the responsibility for elderly care rests within the family (Rowland, 1994). More recently, however, the increase in the numbers of elderly have attracted the attention of government officials. As a result, there has been a call from both researchers and population organizations for future population policy to address the needs of the elderly (especially women), including income, health care and housing arrangements (Nair, 1987; Martin, 1989; ESCAP, 1992; United Nations Sectretariat, 1994).

Many of the demographic and economic changes discussed in this paper have shown that population aging in Asia will place enormous pressures on the traditional family care system, reflecting the potential growth in the demand for services and social programs. Yet many countries are experiencing such enormous increases in the numbers of elderly that society cannot afford to absorb all of the responsibility for and costs of providing for its elderly citizens. The family, especially female members, will remain an important provider of elderly care. Policies and programs on aging should promote and support families as the main elderly care providers (McCallum, 1994; Chang, 1994; Sadik, 1991). It is obvious, however, that families cannot do it all. There is a growing need for services which integrate family care and public assistance.

As the numbers of elderly increase and as people reach older ages, health care needs change. Chronic and disabling conditions dominate the health problems of an older population. Public health and medical care, therefore, will need some reorientation away from communicable diseases toward degenerative diseases and the problems associated with these chronic conditions. 
JENNIFER C. CORNMAN

Education, training and employment programs could also enhance the future social status of the elderly. Hong (1994), for instance, found that, in Beijing women with low literacy tended to be unemployed and economically dependent which, in turn, often translated into a low quality of living, especially among elderly women. Hong (1994) also reported that changes in the family structure further exacerbated the economic vulnerability of older women. An essential measure needed to improve the living conditions and status of elderly women is the enhancement of their education and employment opportunities. Educational attainment, in particular, tends to be associated with a person's economic resources, their ability to interact with complex bureaucratic systems, as well as with their use of programs which affect health and health care utilization (Christenson \& Hermalin, 1992). Educational and employment opportunities will not only elevate the status of women when they are younger, but they will also help to ensure more economic security in old age.

Improvements in the education composition of elderly populations, in turn, will also have implications for implementing polices for the elderly. Christenson and Hermalin (1991) examine the educational composition of the elderly population in five Asian countries. They show that the education composition of the elderly in these countries is changing and will continue to change over the next 25 years. Increasing educational attainment of younger cohorts means that, when these cohorts reach old age, the education composition of the elderly will have improved over the educational characteristics of past elderly cohorts. Policy makers will need to take into consideration these current and future trends. Present policies directed toward an elderly population which is primarily illiterate may be effective today, but may not be an efficient use of resources in the future (Christenson \& Hermalin, 1992).

Population aging in Asia will have significant socioeconomic impacts on society, but these impacts can be forecast now. As noted above, there will be some lag between the onset of fertility decline and significant population aging. Kuroda (1994) points out that many Asian countries will have 20-30 years before dependency ratios reach the levels of the highly aged countries. This time will allow governments, the private sector and individuals to plan and formulate, in advance, programs and policies for an aging society.

\section{CONCLUSIONS}

The purpose of this paper was to show that attaining the goals of or working toward sustainable development will inevitably lead to an aging 
POPULATION AND ENVIRONMENT

population. Reducing fertility leads to smaller birth cohorts and proportions of the population under age 15. Mortality declines, occurring as the result of cleaner water, better nutrition, and other public health measures as well from economic development, will increase the numbers of people surviving to older ages. The combined result of these demographic trends is an aging population.

Developing countries in Asia, and elsewhere, are experiencing rapid increases in the numbers of elderly in their populations. Half of the world's elderly currently lives in developing countries and close to $70 \%$ will be in developing countries in 2025 (Kinsella, 1988). In addition, these elderly populations will be increasingly dominated by women, especially among the oldest old (ages 80 or 85 and over). Yet, there has been little progress in setting priorities for policy development on women and aging (McCallum, 1994).

Many strategies for working toward and involving women in sustainable development will also have an impact on the care and well-being of an aging population. For instance, McClamroch (in this volume) discusses at the aggregate level the impact of educational attainment and labor participation on total fertility rates. She found that labor participation and education together affected levels of fertility. In general, these variables together were associated with lower fertility rates, implying that population growth policies should include components which will promote higher educational attainment and labor participation for women.

Mehra (in this Volume), discusses the importance of involving women in sustainable development. She notes that the success of development plans depends on recognizing the roles that women play in resource use and economic production. Fully integrating women into the development process also has important implications for women in an aging population. Education, training and employment opportunities are not only important for women's current status, but they also have implications for women's roles as caregivers and for the well-being of women in old age. As governments develop policies for attaining sustainable development they need to keep in mind how these policies affect women currently as well as how an aging population will affect people across the life course. It is clear that policies which address the needs of an aging population should be developed or at least considered.

\section{ACKNOWLEDGMENTS}

I would like to thank Albert Hermalin and John Cornman for their comments and suggestions. 
JENNIFER C. CORNMAN

\section{ENDNOTES}

1. Other factors such as migration can also affect the age structure of a population. However, in this examination of the effects of fertility and mortality declines on population age structure, a population closed to migration is assumed.

2. Although there is some debate, many demographers attribute initial declines in mortality to improved nutrition, better housing, cleaner water and food supplies as well as to the introduction of some Western medicine (Preston, 1980).

3. Mortality can affect the numbers being born into a population by reducing the number of women who reach childbearing years. Fewer female babies will reach childbearing ages under a high mortality regime than under a low mortality regime.

4. Replacement level fertility is reached when the Total Fertility Rate (TFR) equals 2.1 and the Net Reproduction Rate (NRR) equals 1.0. A TFR of 2.1 means that if a woman were to experience the current age-specific fertility rates she would have, on average, 2.1 children. An NRR of 1.0 means that if a woman experienced current fertility and mortality conditions throughout her child-bearing years, she would have, on average, one daughter who would survive to child-bearing age and give birth to one daughter.

5. The speed of a decline in fertility will also impact the rate at which a population ages, but the point of this illustration is to show how declines in the level of fertility significantly impact the age structure of the population. The timing of this fertility decline reflects the UN (1993) projection of the fertility decline in India from 1990 to 2030.

6. Demographers generally discuss three types of dependency ratios. One is the overall dependency ratio which is the ratio of the number of people age $0-14$ and over 65 to the number of people age 15-64. The old age dependency ratio is the ratio of the number of people age 65 and over to the number of people age 15-64. The young dependency ratio is the ratio of the number of people age $0-14$ to the numbers age 15-64.

7. The sex ratio among the elderly is the number of males age 65 and over per 100 females age 65 and over.

8. It should be noted, however, that changes in patterns of co-residence may not necessarily mean a decline in support. Hermalin et al (1992) find that in Taiwan, although there has been a trend away from coresidence in recent decades in Taiwan, a high proportion of elderly continue to coreside with one or more children. For those elderly who do not coreside with adult children, a large majority of them have at least one child who lives close by. Despite the changes in living arrangements, the elderly in Taiwan tend to maintain a high degree of contact with family members.

\section{REFERENCES}

Chayovan, N. (1994, March). Consequences and implications of demographic change in Thailand. In Consequences and implications of demographic change. Session conducted at the Japanese Organization for International Cooperation in Family Planning, Inc. Workshop on Population Aging: Women in an Aging Society, Singapore.

Chang, T.P. (1994, March). Financial security in old age for women in Malaysia. In Economic characteristics of women and financial security. Session conducted at the lapanese Organization for International Cooperation in Family Planning, inc. Workshop on Population Aging: Women in an Aging Society, Singapore.

Chanana, H.B. \& Talwar, P.P. (1986). Implications of demographic goals in 2000 AD for aging population in India. Health and Population: Perspectives and Issues 9(2), 67-97.

Christenson, B. \& Hermalin, A.l. (1991). Comparative analysis of the changing educational composition of the elderly population in five Asian countries: A preliminary report. Com- 


\section{POPULATION AND ENVIRONMENT}

parative study of the elderly in Asia: Research report No. 91-11. Ann Arbor: Population Studies Center, University of Michigan.

Domingo, A. (1994, March). Women's role in the family support system in the Philippines. in Women's role in the family support system. Session conducted at the lapanese Organization for International Cooperation in Family Planning, Inc. Workshop on Population Aging: Women in an Aging Society, Singapore.

Domingo, L. (1992). The filipina elderly in development: Status and prospects. Comparative study of the elderly in Asia: Research report No. 92-21. Ann Arbor: Population Studies Center, University of Michigan.

Domingo, L. (1994, March). The Family and Women in an Aging Society: The Philippines. In Family and Women in an Aging Society. Session conducted at the Japanese Organization for International Cooperation in Family Planning, Inc. Workshop on Population Aging: Women in an Aging Society, Singapore.

Economic and Social Commission for Asia and the Pacific (1989). Demographers's Notebook: Sustainable Development. Asia-Pacific Population Journal 4(3), 71-74.

Economic and Social Commission for Asia and the Pacific (1992, September). Productive aging in Asia and the Pacific. Proceedings from the expert group meeting on local-level policy development for dealing with the consequences of population aging. New York: United Nations.

Fricke, T., Liu, P.K.C., Thonton, A., Freedman, D., \& Yang, L.S. (1994). The changing organization of individual activities. in A. Thornton and H.S. Lin (Eds.). Social change and the family in Taiwan, pp. 116-145. Chicago: Chicago University Press.

Goldman, N. (1986). Effects of mortality levels on kinship. In United Nations (Ed.). Consequences of mortality trends and differentials, pp. 79-87. New York: United Nations.

Hashimoto, A. (1991). Living arrangements of the aged in seven developing countries: A preliminary analysis. Journal of Cross-Cultural Cerontology 6, 359-381.

Hermalin, A.I., Ofstedal, M.B., \& Chang, M.C. (1992). Types of support for the aged and their providers in Taiwan. Comparative study of the elderly in Asia: Research report No. $92-$ 14. Ann Arbor: Population Studies Center, University of Michigan.

Hermalin, A.I., Ofstedal, M.B., \& Chi, L. (1992). Kin availability of the elderly in Taiwan: Who is available and where are they? Comparative study of the elderly in Asia: Research report No. 92-18. Ann Arbor: Population Studies Center, University of Michigan.

Hermalin, A.I., Ofstedal, M.B., \& Lee, M.L. (1992). Characteristics of children and intergenerational transfers. Comparative study of the elderly in Asia: Research report No. 9221. Ann Arbor: Population Studies Center, University of Michigan.

Hong, L.X. (1994). Living Status of Old Women. In Social services and provisions. Session conducted at the Japanese Organization for International Cooperation in Family Planning, Inc. Workshop on Population Aging: Women in an Aging Society, Singapore.

Kinsella, K. (1988). Aging in the Third World. Washington, D.C.: United States Bureau of the Census.

Kitatani, K. (1990, November). Population and environment impacts on quality of life. In Human population dynamics and resource demand. Workshop conducted at the 18th Session of the General Assembly of IUCN - The World Conservation Union, Perth, Australia.

Kuroda, T. (1994, March). Welcoming address. Opening session at the Japanese Organization for International Cooperation in Family Planning, Inc. Workshop on Population Aging: Women in an Aging Society, Singapore.

Lee, Y.J. \& Palloni, A. (1992). Changes in the family status of elderly women in Korea. Demography 29(1), 69-91.

Martin, L. (1989). Living arrangements of the elderly in Fiji, Korea, Malaysia, and the Philippines. Demography 26(4), 627-42.

Martin, L. 1990. The status of South Asians growing elderly population. Journal of Cross Cuitural Gerontology 5, 93-117

Mehta, K. (1994, March). Women's role in family support system in Singapore. In Women's role in family support system. Session conducted at the Japanese Organization for Inter- 
JENNIFER C. CORNMAN

national Cooperation in Family Planning, Inc. Workshop on Population Aging: Women in an Aging Society, Singapore.

McCallum, 1. Rapid aging in Asia: Consequences and implications for women. In Consequences and implications of demographic changes. Session conducted at the Japanese Organization for International Cooperation in Family Planning, Inc. Workshop on Population Aging: Women in an Aging Society, Singapore.

Nair, S.P. (1987). Effect of declining fertility on population aging in India: An application of Coale's analytical model. Genus 43(3-4), 175-82.

Ness, G. (Forthcoming). Population and strategies for national sustainable development: $A$ handbook for assisting national policy makers in population and planning process. New York: UNFPA.

Preston, S. (1980). Causes and consequences of mortality declines in LDCs during the 20th century. In R. Easterline (Ed.). Population and economic changes in developing countries, pp. 289-341. Chicago: University of Chicago Press.

Rowland, D.T. (1994). Population policies and aging in Asia: A cohort perspective. In The aging of Asian populations, proceedings of the United Nations Round Table on Aging of Asian Populations, Bangkok, 4-6 May 1992. New York: United Nations.

Sadik, N. (1991). Population policies and programs: Lessons learned from two decades of experience. New York: Published for the United Nations Population Fund by New York University Press.

Stolnitz, G. (1982). Post World War II trends. In Ross (Ed.). The international encyclopedia of population, pp. 461-69. New York: Free Press.

United Nations. (1993). World Population Prospects: 1992 Revision. New York: United Nations.

United Nations, Department of Economic and Social Development. (1993). The sex and age distribution of the world populations: The 1992 revision. New York: United Nations.

United Nations Sectretariat. (1994). Overview of recent research findings on population ageing and the family. in Department for Economic and Social Information and Policy Analysis (Ed.). Aging and the family: Proceedings of the United Nations International Conference on Aging Populations in the Context of the Family, Kitakyushu, Japan, 15-19 October 1990, pp. 79- 104. New York: United Nations.

Watana, P. (1994, March). Economic characteristics of women and financial security in Thailand. In Economic characteristics of women and financial security. Session conducted at the Japanese Organization for International Cooperation in Family Planning, Inc. Workshop on Population Aging: Women in an Aging Society, Singapore.

Watkins, S.C., J.A. Menken, \& Bongaarts, J. (1987). Demographic foundations of family change. American Sociological Review 52, 346-358.

Young, C. 1986. The residential life cycle: Mortality and morbidity effects on living arrangements. In United Nations (Ed.). Consequences of mortality trends and differentials, 10112. New York: United Nations. 